\title{
The Mormyromast Region of the Mormyrid Electrosensory Lobe. II. Responses to Input From Central Sources
}

\author{
Claudia Mohr, Patrick D. Roberts, and Curtis C. Bell \\ Neurological Sciences Institute, Oregon Health and Sciences University, Beaverton, Oregon 97006
}

Submitted 6 March 2003; accepted in final form 21 April 2003

\begin{abstract}
Mohr, Claudia, Patrick D. Roberts, and Curtis C. Bell. The mormyromast region of the mormyrid electrosensory lobe. II. Responses to input from central sources. J Neurophysiol 90: 1211-1223, $2003 ; 10.1152 /$ jn.00213.2003. This is the second in a series of two papers on the mormyromast regions of the electrosensory lobe (ELL) of mormyrid electric fish. In this study, we examined the effects of artificial stimulation of two of the three major central inputs to ELL on different morphologically identified cell types of ELL. The three major central inputs to ELL are the eminentia granularis posterior, the juxtalobar nucleus, and the preeminential nucleus. We stimulated the juxtalobar and preeminential nuclei. We compared the effects of such stimulation with effects of the electric organ corollary discharge (EOCD) on the same cells to understand the origins of EOCD effects in ELL. Responses to juxtalobar stimulation were different in different cell types and remarkably similar to corollary discharge responses in the same cells. In addition, responses to juxtalobar stimulation were consistently depressed when the stimulus was delivered immediately after the naturally occurring EOCD response. These findings indicate that the juxtalobar nucleus is a major source of the EOCD responses of ELL cells. In contrast, preeminential stimulation evoked similar responses in medium ganglionic cells, and the two types of efferent cells that were quite different from the EOCD responses of these cells, suggesting that the preeminential nucleus is less important than the juxtalobar nucleus in determining the EOCD responses of ELL cells. Preeminential responses of medium ganglionic and efferent cells consisted of a short-latency excitatory postsynaptic potential (EPSP) followed by a long-lasting inhibitory postsynaptic potential (IPSP). Both the EPSPs and IPSPs were facilitated when brief bursts of closely spaced stimuli were delivered.
\end{abstract}

\section{N T R O D U C T I O N}

This is the second in a series of two papers on the interaction between peripherally and centrally originating inputs to the electrosensory lobe (ELL) of mormyrid electric fish. Both papers examine the regions of ELL that receive input from mormyromast electroreceptors, the electroreceptors that are responsible for active electrolocation. The papers focus on the central inputs that convey corollary discharge signals associated with the motor command that elicits the electric organ discharge in these fish (electric organ corollary dischargeEOCD). The previous paper examined the effects of electrosensory stimuli and EOCD signals on different types of morphologically identified neurons in ELL. In this paper, we investigate the origins of the corollary discharge effects in ELL by recording intracellularly from the different cell types of

Address for reprint requests: C. Mohr, Neurological Sciences Institute, Oregon Health and Sciences Univ., 505 N.W. 185th Ave., Beaverton, OR 97006 (E-mail: mohrc1@ohsu.edu).
ELL and electrically stimulating two of the three central structures that send corollary discharge signals to ELL, the juxtalobar and preeminential nuclei. We compare the responses to such artificial stimulation with responses to the EOCD itself.

A summary diagram of the different central inputs to ELL inputs is shown in Fig. 1. The juxtalobar nucleus is a small nucleus located at the anterior ventral border of ELL. The medial part of this nucleus projects bilaterally to the deeper layers of ELL, and the lateral part projects to the ipsilateral EGp (Bell et al. 1981). The cells of this nucleus give a single spike at a short, fixed delay following the EOD motor command (Bell and von der Emde 1995). Electrosensory stimuli have no effect on this EOCD response. The field potentials evoked by stimulation of juxtalobar nucleus are very similar in waveform and laminar distribution to the EOCD-evoked waveforms, and bilateral lesions of the juxtalobar nucleus cause a dramatic reduction in the EOCD-evoked potentials, although they do not abolish these potentials altogether (Bell and von der Emde 1995). These previous results suggest that the juxtalobar nucleus is a major determinant of the EOCD responses of ELL cells.

The preeminential nucleus is a large nucleus at the border between the medulla and the mesencephalon. The nucleus receives electrosensory input from both ELL and from higherorder electrosensory structures and is thus responsible for the feedback of higher order electrosensory information to ELL (Bell et al. 1981). The nucleus affects ELL directly via a prominent bilateral projection to the ventral molecular layer and via a sparser and poorly understood contralateral projection to the granular layers of ELL. The nucleus also affects ELL indirectly via bilateral projections to the eminentia granularis posterior (EGp), a mass of granule cells that covers much of ELL and that provides the parallel fibers of the ELL molecular layer (Bell and Szabo 1986; Maler 1973). The cells of the preeminential nucleus are affected by the EOCD as well as by electrosensory stimuli (von der Emde and Bell 1996). The EOCD evokes a brief burst of spikes in these cells that is modulated by electrosensory stimuli given at the time of the EOD.

The EGp is a third source of corollary discharge input to ELL. The EGp receives corollary discharge signals from the preeminential and juxtalobar nuclei as well as from a nucleus known as the paratrigeminal command associated nucleus (Bell et al. 1981). The EGp also receives proprioceptive input,

\footnotetext{
The costs of publication of this article were defrayed in part by the payment of page charges. The article must therefore be hereby marked "advertisement" in accordance with 18 U.S.C. Section 1734 solely to indicate this fact.
} 


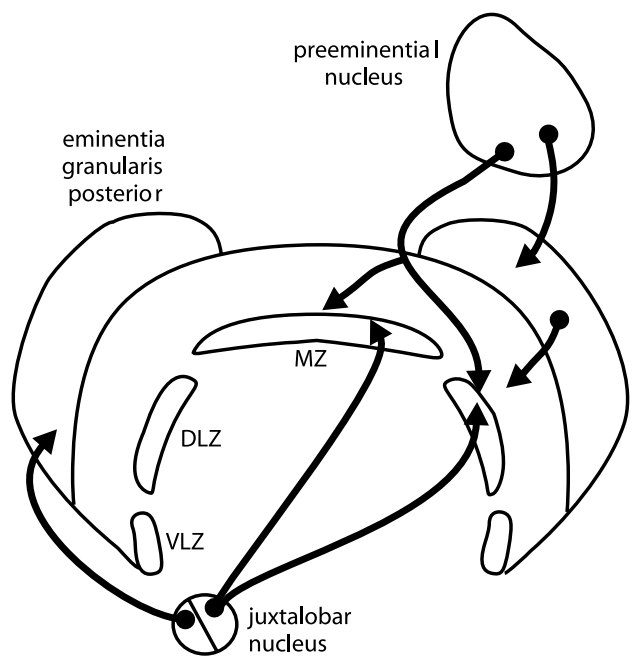

FIG. 1. Schematic diagram of the central inputs into the mormyromast regions of electrosensory lobe (ELL). DLZ, dorsolateral zone; MZ, medial zone; VLZ, ventrolateral zone.

mechanical lateral line input, and electrosensory input. Electrosensory input affects EGp via a direct projection from cells in the deeper layers of ELL (unpublished observations of J. Meek, K. Grant, and C. C. Bell) as well as via electrosensory modulation of the EOCD bursts in fibers from the preeminential nucleus. In this study, we did not stimulate the granule cells of EGp or the parallel fibers of ELL that the granule cells give rise to. Parallel fibers of ELL have been electrically stimulated, however, in in vitro studies of ELL (Grant et al. 1998). Such electrical stimulation of parallel fibers evokes excitatory postsynaptic potentials (EPSPs) and EPSP-inhibitory postsynaptic potential (IPSP) sequences in all of the cells with dendrites in the molecular layer.

\section{METHO D S}

The same ELL cell recordings were used for this study and for the study described in the first paper of the series. The first paper should therefore be consulted for most of the methods, including the morphological and physiological identification of the different cell types. All experiments that were performed in this study adhere to the APS's Guiding Principles in the Care and Use of Animals and were approved by the IACUC.

\section{Electrical stimulation}

This paper describes the responses of ELL cells to electrical stimulation of the juxtalobar and preeminential nuclei. Stimuli were delivered using monopolar tungsten microelectrodes that were insulated except at the tip. The stimulus electrodes were positioned in the contralateral juxtalobar and ipsilateral preeminential nuclei using EOCD-evoked field potentials as a guide. Both projections are bilateral [15 /id (Bell et al. 1981); 20 /id (Bell and von der Emde 1995)], and lack of space makes it impossible to stimulate both nuclei on the same side. Field potentials characteristic of each nucleus had been established in previous studies (Bell and von der Emde 1995; von der Emde and Bell 1996). The optimal field potentials were initially located using low-resistance micropipettes filled with $3 \mathrm{M} \mathrm{NaCl}$ to minimize damage to the brain. Tungsten stimulating electrodes were then placed at the same location and the EOCD field potentials were recorded again.

The EOCD field potential that we used to locate the juxtalobar nucleus consisted of two brief spike-like potentials that were highly time locked to the EOD motor command (Fig. 2A) (Bell and von der Emde 1995). The EOCD field potential that we used to locate the preeminential nucleus was a sharply falling negative wave with an onset latency of 8-10 ms (Fig. 2C) (von der Emde and Bell 1996). Brief bursts of spikes were usually superimposed on the field potential.

The effectiveness of juxtalobar and preeminential stimuli were tested prior to intracellular recording by recording extracellular field potentials in ELL with low-resistance micropipettes (Fig. 2, $B$ and $D$ ). The stimuli evoked field potentials in the different layers of ELL that were similar to those obtained in previous studies of these nuclei (Bell and von der Emde 1995; von der Emde and Bell 1996) (see also following text). The ability to elicit these field potentials provided an additional means of confirming the desired location of the stimulating electrodes.

We assume that the effects of our preeminential stimulation were predominantly due to activation of the direct projection to the deep molecular layer of ELL. Our preeminential stimulus evoked a brief, short-latency negative wave in ELL that was largest in the deep molecular layer (Fig. 2D) and that inverted to a small positive wave in the outer molecular layer as described previously (Bell and von der Emde 1995). The short latency, brief duration, and laminar distribution of the field indicated that the responses were mainly due to the direct projection rather than to the indirect projection through EGp. If activation of the indirect projection to ELL through EGp had been prominent, we would have observed a longer-latency negative wave in the outer molecular layer where parallel fibers from EGp terminate. Our stimulus did not activate the sparse projection from preeminentialis to the granular layer of ELL because this projection is exclusively contralateral (C. C. Bell, unpublished observations), and our stimulus was on the ipsilateral side.

We used negative current pulses $(0.1 \mathrm{~ms}, 6-30 \mu \mathrm{A})$ to evoke the field potentials and to evoke synaptic responses from intracellularly recorded ELL cells. Current was passed between the tungsten electrode and an $\mathrm{Ag}-\mathrm{AgCl}$ indifferent electrode in the skin close to the
A
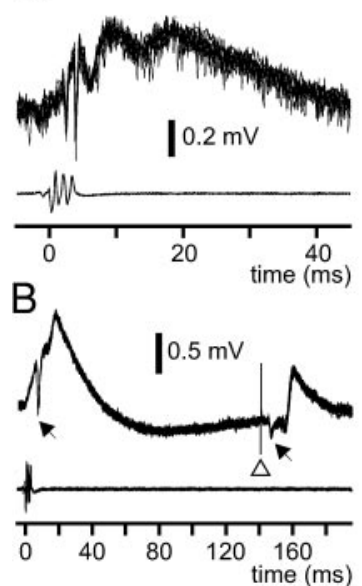

C
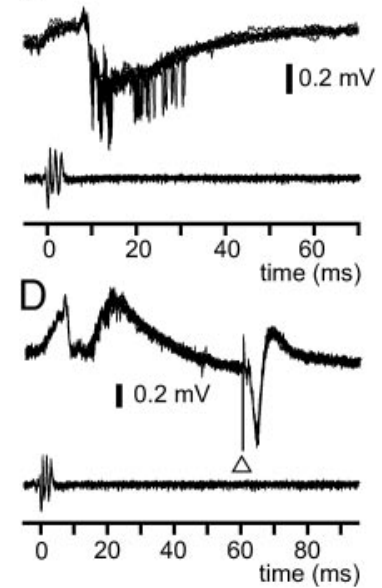

FIG. 2. Field potentials. $A$ : field potential recorded in the juxtalobar nucleus in response to the electric organ corollary discharge (EOCD). The 1st peak (at 2.1-2.8 ms) is considered to be the afferent input into the nucleus, whereas the 2nd (at 3.9-5 ms) represents the firing of the juxtalobar cells themselves (Bell and von der Emde 1995). Ten superimposed traces. $B$ : field potentials recorded in the deep granular layer of ELL in response to the EOCD and to stimulation of the juxtalobar nucleus $(\triangle)$. $\uparrow$, a sharp initial component that is larger in the response to the EOCD than in the response to juxtalobar stimuli. The initial positive component of the EOCD response, seen here and also in $D$ is due to EOCD activation of the eminentia granularis posterior (Bell and von der Emde 1995). $C$ : field potentials recorded in nucleus preeminentialis in response to the EOCD. Spikes of preeminential cells were recorded extracellularly at the same time. $D$ : field potentials recorded in the ganglionic layer of ELL in response to the EOCD and in response to a preeminential stimulus $(\triangle)$. 
ipsilateral recording site. Stimuli were usually given between 60 and $100 \mathrm{~ms}$ after the command signal to minimize interaction with EOCDevoked responses, although stimuli were also sometimes delivered at shorter delays of 10-20 ms to examine such interaction. The shock artifact associated with stimulation of the juxtalobar nucleus was often quite large because the nucleus is immediately adjacent to ELL. The artifact made it difficult to determine the onset latency of juxtalobarevoked synaptic potentials, in which case the latency of the peak of the potential was measured.

\section{Anatomical methods}

We verified the stimulation sites histologically by making small lesions at the tips of each stimulating electrode after the experiments (2- to $3-\mu \mathrm{A}$ DC current for $3 \mathrm{~min}$ ). The juxtalobar nucleus is a small group of cells, and lesions made with electrodes directed at this structure made holes in the tissue that usually obliterated most of the nucleus but that nevertheless showed that the electrodes had been accurately positioned. All of the lesions made with stimulus electrodes directed at the preeminential nucleus were within the nucleus with most of them being located in the medial or hilar region of the structure.

A separate series of anatomical experiments was carried out in three fish to determine the morphology of juxtalobar terminals in ELL. Biotinylated dextran amine (BDA; 3,000 MW, Molecular Probes) was dissolved in $0.7 \% \mathrm{NaCl}$ ( $3 \%$ solution) and was injected by iontophoresis ( $4 \mu \mathrm{A}$ for $5 \mathrm{~min})$ into the juxtalobar nucleus. The location of the nucleus was determined by recording the characteristic EOCD-evoked field potential as described in the preceding text. The fish were allowed to recover from the surgery after the injections and to survive for 3 days before being reanesthetized and perfused. The histological procedures were the same as for the experiments with intracellular filling.

\section{RE S U L T S}

\section{Morphology of juxtalobar fibers}

We examined the morphology of juxtalobar terminals in ELL to help us understand the effects of juxtalobar input on
ELL circuitry. Injections of biotinylated dextran into the juxtalobar nucleus resulted in the labeling of a dense network of fine fibers in the medial and dorsolateral zones of ELL (Fig. 3). No terminals were observed in the ventrolateral zone where primary afferents from ampullary electroreceptors terminate, suggesting that the juxtalobar nucleus projects exclusively to the mormyromast regions of ELL.

The fibers from the juxtalobar nucleus had many swellings along their length, which could be synaptic terminals (Fig. 3, inset). Most of the fibers and presumed terminals were in the deep and superficial granular layer, but some fibers extended up into the plexiform, ganglionic, and deep molecular layer, suggesting that other elements besides granular cells could be directly excited by juxtalobar input.

\section{Field potentials in response to stimulation of central afferents}

We recorded extracellular field potentials in response to juxtalobar and preeminential stimuli. Field potentials reflect activity in the entire local circuit. The recording of field potentials therefore allowed us to assess some of the global features of ELL responses to stimulation of central afferents.

JUXTALOBAR STIMULATION. Stimulation of the juxtalobar nucleus evokes field potentials in ELL that vary markedly according to the recorded layer in a manner that corresponds to the variations in EOCD-evoked potentials as described previously (Bell and von der Emde 1995). The shortest latency response is a sharp negative wave in the granular layer (Fig. 4), consistent with the fact that the fibers from the juxtalobar nucleus terminate mainly in this layer (Fig. 3).

The EOCD response of cells in the juxtalobar nucleus consists of a single spike that occurs with each motor command at a short fixed latency, of 4-4.6 ms after $t_{0}$ (Bell and von der Emde 1995). Because the normal output of the nucleus is a single spike, we used only a single stimulus in testing the effect

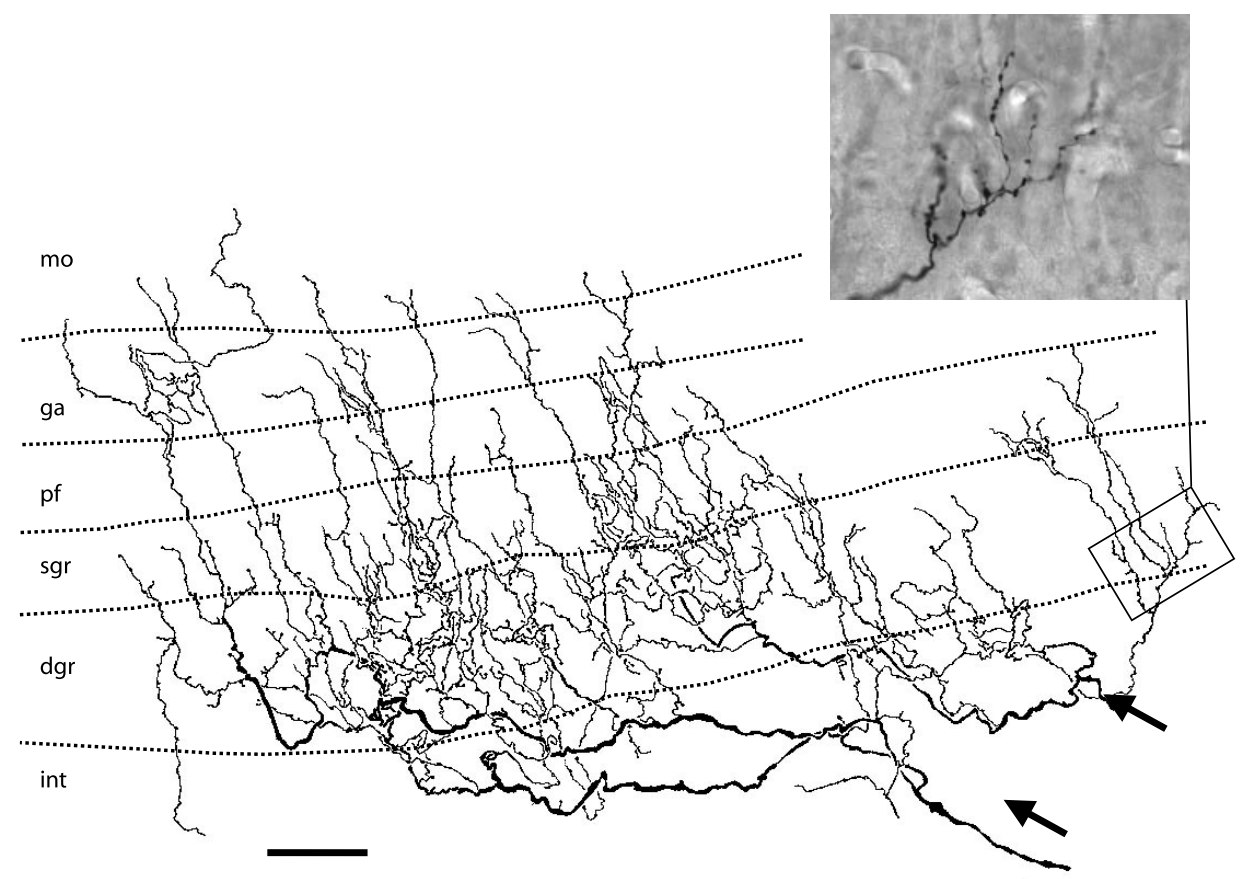

FIG. 3. Reconstruction of part of the terminal field of 1 branch of a juxtalobar axon in ELL. The rostrocaudal extent of this branch was $400 \mu \mathrm{m} . \leftarrow, 2$ main branches coming off a single axon. Although most of the termination is in the superficial (sgr) and deep granular (dgr) layers, a few axonal branches also extend into the plexiform (pf), ganglionic (ga), and deep molecular layer (mo). Borders of the layers are indicated by dotted lines. Inset: a photograph of apparent terminals in the region of the axon indicated by a box in the drawing. Bar: $50 \mu \mathrm{m}$. 

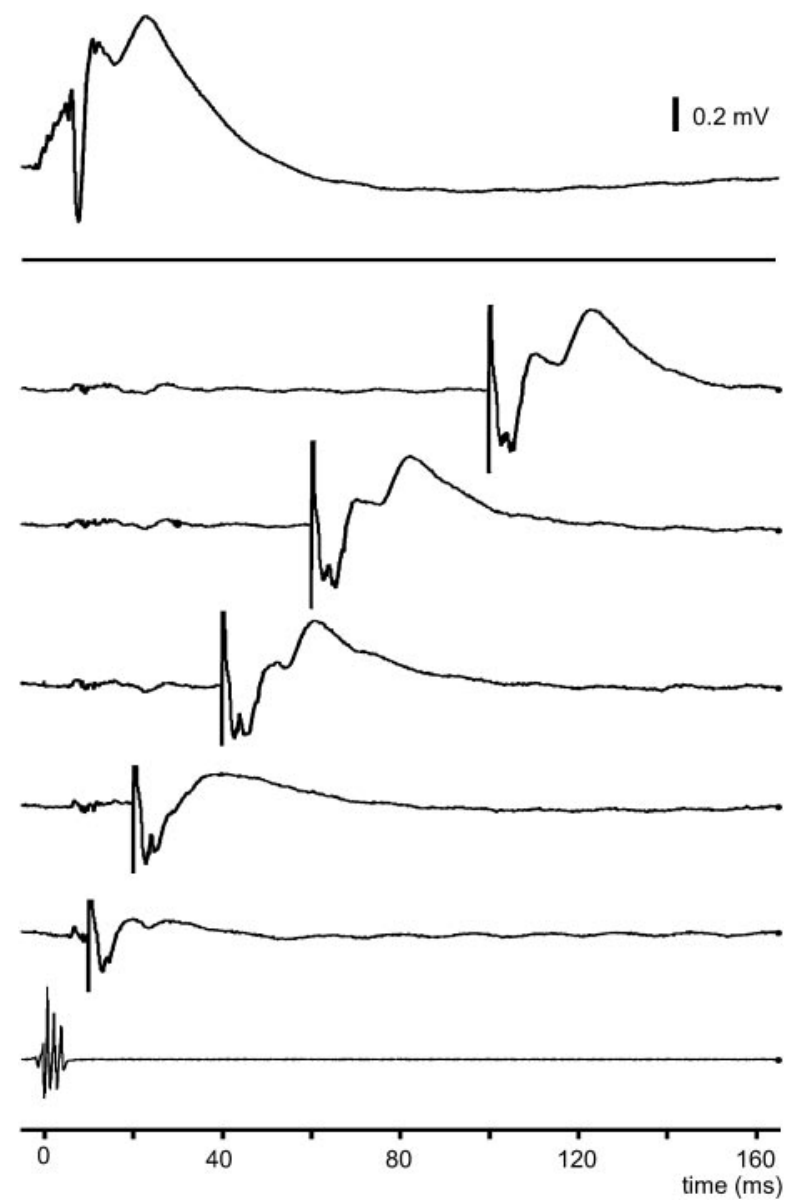

FIG. 4. Field potentials recorded in the deep granular layer of ELL in response to the EOCD (top) and in response to juxtalobar stimuli at different delays after the command signal. The EOCD response was subtracted from the 5 bottom traces to show the juxtalobar responses more clearly. Note the smaller size of the juxtalobar response when stimuli were given at short delays.

of juxtalobar stimulation. We found that the field potential response to juxtalobar stimulation is strongly depressed when stimuli are given at short delays following the command signal (Fig. 4). This depression is consistent with juxtalobar input being a major determinant of the EOCD responses in ELL, the response to an artificial juxtalobar input being reduced when the artificial input arrives immediately after the natural, EOCD-evoked juxtalobar input.

PREEMINENTIAL STIMULATION. As described previously (Bell and von der Emde 1995), a single stimulus to the preeminential nucleus evokes a brief, short-latency, negative-going field potential that is largest in the deep molecular layer (Figs. $2 B$ and 5, $A$ 1st trace, and $B$ ). Recordings in the preeminential nucleus show that most preeminential cells respond to the EOCD with a burst of two to five spikes in which the spikes occur at intraburst intervals of 2-4 ms (von der Emde and Bell 1996) (see also following text). We therefore tested the effects of stimulating the preeminential nucleus with similar bursts of closely spaced stimuli. Such stimulation resulted in marked facilitation of the field potential response to preeminential stimulation (Fig. 5A, left). Responses in ELL to two, three, or four stimuli in preeminentialis were clearly much larger than would be expected from the summation of responses to individual stimuli (see Fig. 5A, right). Increasing the number of stimuli beyond five did not cause any further enhancement. Similar facilitation of the ELL response to preeminential stimulation with brief bursts of stimuli has been observed in gymnotiform fish (Bastian 1996; Berman et al. 1997; Oswald et al. 2002).

The response to preeminential stimulation was enhanced by the EOD motor command (Fig. 5B), in contrast to the depression that was observed with juxtalobar stimuli. Responses were largest when stimuli were given at delays of $\sim 20 \mathrm{~ms}$ with respect to the command (Fig. 5B, 3rd trace). The enhancement could also be due to delivery of the artificial preeminential stimulus during or just after the naturally occurring EOCDevoked burst of spikes in preeminential axons and could thus be caused by the same mechanism that causes facilitation of responses to bursts of closely spaced stimuli. Alternatively, the command-associated enhancement could also be due to other EOCD inputs to ELL.

\section{Recordings of central afferents in ELL}

Recordings from the juxtalobar and preeminential nuclei have shown how the cells in these nuclei respond to the EOCD and to electrosensory stimuli. In this study, we recorded extracellularly from the two types of central afferents near their terminals in ELL, allowing us to establish the timing of EOCD responses of these afferents in the ELL itself and to confirm that our stimuli activated these afferents.

RECORDINGS OF JUXTALOBAR FIBERS. We recorded extracellularly from four fibers in the granular layer of ELL that had the same response properties as neurons recorded in the juxtalobar nucleus (Bell and von der Emde 1995). The fibers responded to the EOCD with single spikes at short fixed latencies of 5.6-5.8 ms (Fig. 6A, left). The latency of the spike in any one fiber was time-locked to the motor command with great precision, showing $<0.1 \mathrm{~ms}$ of jitter. The single EOCD-evoked spike was the only activity in these fibers and electrosensory stimuli had no effect. All of these properties match those of cells recorded in the juxtalobar nucleus (Bell and von der Emde 1995). The EOCD response of cells in the juxtalobar nucleus is a single spike at a fixed latency of $\sim 3.7-4.1 \mathrm{~ms}$, indicating that it takes between 1.5 and $2.1 \mathrm{~ms}$ for an action potential to be conducted from the juxtalobar nucleus to ELL.

The fibers responded with a time-locked spike to electrical stimulation of the juxtalobar nucleus, providing a further indication that the fibers originate from that structure (Fig. $6 A, \leftarrow)$. The latency of this spike was $4.2 \mathrm{~ms}$ (in all recorded fibers), considerably longer than the 1.5-2.1 $\mathrm{ms}$ that would be expected if the juxtalobar cells were directly and immediately activated by the artificial electrical stimulus. Perhaps the electrical stimulus activated excitatory afferents to juxtalobar cells rather than the cells themselves as occurs in other systems (Gustafsson and Jankowska 1976) or the utilization time (the time between current injection and an action potential) is particularly long in the juxtalobar nucleus.

RECORDINGS FROM PREEMINENTIAL FIBERS. We recorded extracellularly from 26 fibers in the deep molecular layer of ELL that had the same properties as cells recorded in the preeminential nucleus (von der Emde and Bell 1996). All of the activity of these fibers was EOCD evoked. There was no 


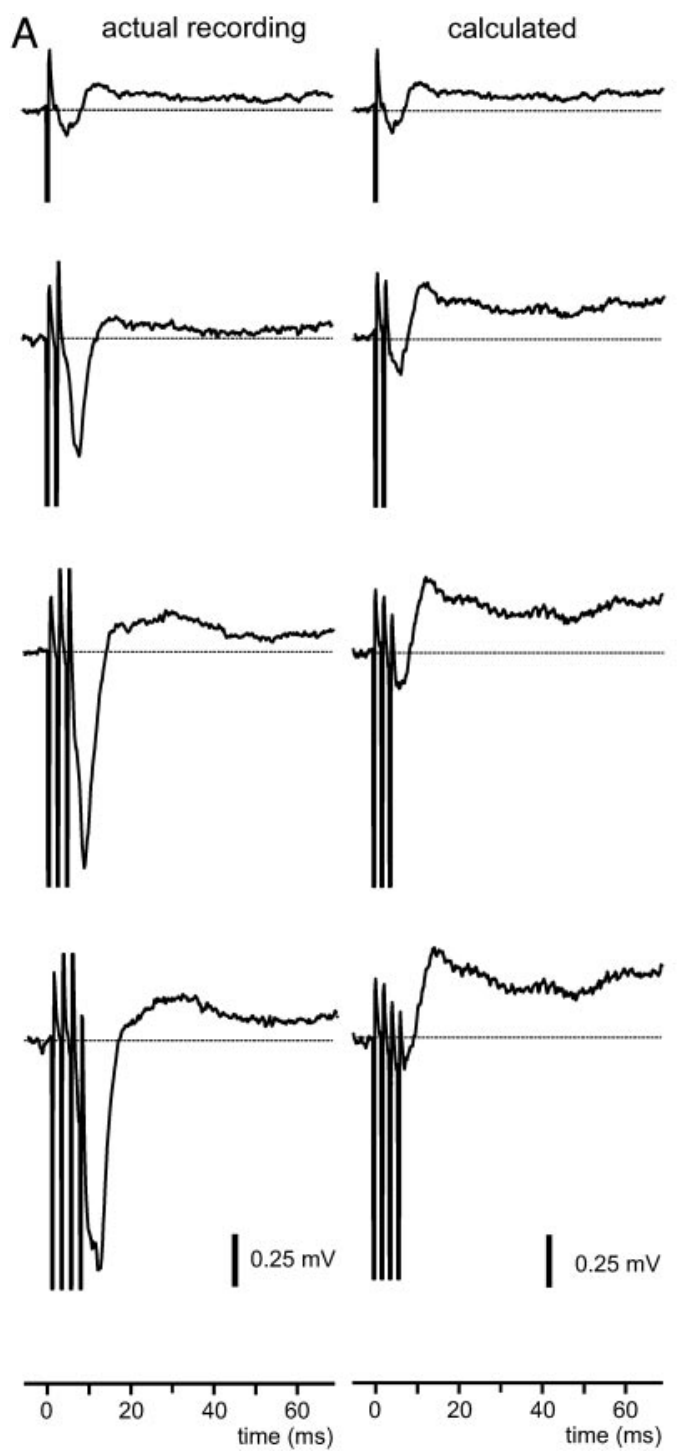

spontaneous activity at long delays after the EOD motor command. Some of the fibers responded with a single spike (Fig. $6 B b$, left $)$, whereas others responded with a burst of spikes to the EOCD (Fig. $6 B, b$ and $c$, left), with first spike latencies varying between 10 and $16 \mathrm{~ms}$ (mean, $12.3 \pm 2.1 \mathrm{~ms}$ ). The responses of some fibers were rather variable in latency (Fig. $6 B, a$ and $b$ ) whereas the responses of others were quite time locked (Fig. 6Bc).

Preeminential cells receive electrosensory input from ELL, and the EOCD bursts of these cells are affected by electrosensory stimuli (von der Emde and Bell 1996). We therefore tested the effects of local electrosensory stimuli in 8 of the 24 fibers recorded in ELL. The stimuli were single brief pulses given 4.5 ms after $t_{0}$, the delay at which the EOD would normally occur (see METHODS of the 1st paper in this series for a description of how electrosensory stimuli were delivered). Thresholds for the electrosensory effects were between 10 and $20 \mu \mathrm{A}$. The effects of electrosensory stimuli were clearly excitatory in five fibers. In these fibers, a sensory stimulus caused an increase in the number of spikes beyond the number evoked by the EOCD alone. Inhibitory effects of an electrosensory stimulus were observed in three fibers. In one of these fibers, the electrosen-
FIG. 5. Field potentials recorded in the deep molecular layer of ELL in response to stimulation of the preeminential nucleus. A: facilitation of the preeminential response with brief bursts of stimuli. Left: actual responses to 1-4 stimuli. Right: calculated responses (derived by simply summing the response to a single stimulus to $1,2,3$, or 4 times) showing the responses that would be expected if there were no facilitation. $B$ : EOCD facilitation of the preeminential response. Responses to single preeminential stimuli at different delays following the command signal. Time zero $\left(t_{0}\right)$ is indicated by the vertical stippled line and the recording of the command signal in the bottom trace. The field potential in response to the EOCD was subtracted to show the preeminential response more clearly. sory stimulus blocked the EOCD-evoked burst completely. Receptive fields extended over several square centimeters of body surface. Such effects of electrosensory stimuli on EOCD responses are similar to the effects of electrosensory stimuli on EOCD responses of preeminential cells (von der Emde and Bell 1996).

We stimulated the preeminential nucleus while recording from these fibers in the deep molecular layer to further test our hypothesis that these were indeed fibers from the preeminential nucleus. All 24 fibers responded with a shortlatency time-locked spike to the stimulus (thresholds: 1.5$21 \mu \mathrm{A}$ ). Spike latencies varied between 0.7 and $4 \mathrm{~ms}$ (Fig. $6 B$, right). The shortest latencies of $\leq 1.0 \mathrm{~ms}$ (Fig. 6Ba) indicate that the stimulus activated the preeminential cells or fibers directly because chemical synapses in cold blooded vertebrates at room temperature have delays of $\sim 1 \mathrm{~ms}$, and some time is required for conduction of the impulse to ELL. The longer-latency responses could include synaptic delays and could be due to activation of fibers in the nucleus that are presynaptic to preeminential cells. In either case, the low-threshold responses with short fixed latencies are con- 

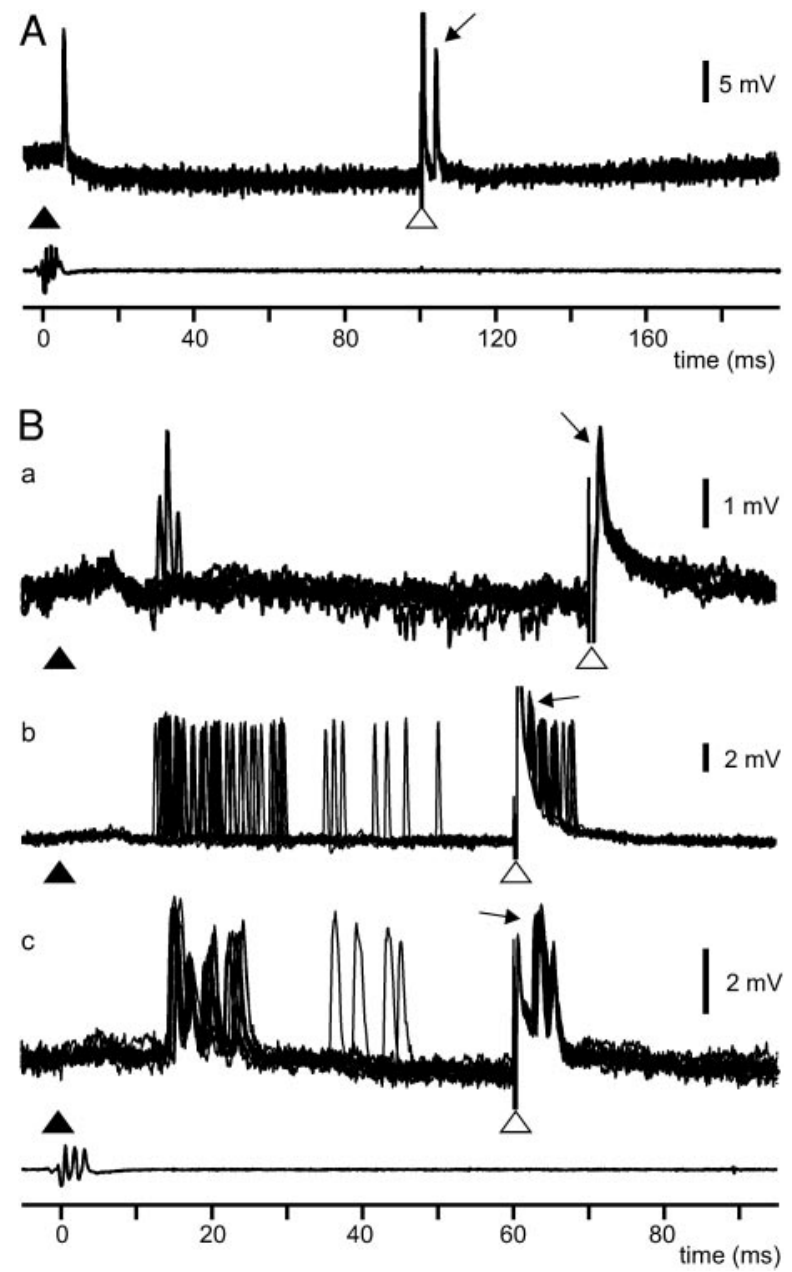

FIG. 6. Extracellular recordings in ELL of fibers from the juxtalobar and preeminential nuclei. $A$ : juxtalobar fiber. Responses to the EOCD and response to juxtalobar stimulation. Ten superimposed traces. $\mathbf{\Delta}, t_{0} ; \Delta$, time of central stimulation. Note that both responses are highly time-locked. $B$ : preeminential fibers. Responses to the EOCD and to single preeminential stimuli. Ten superimposed traces. $a$ : preeminential fiber with an occasional spike in response to the EOCD and short-latency $(0.7 \mathrm{~ms})$ spike in response to the preeminential stimulus. $b$ : preeminential fiber with bursts of spikes in response to the EOCD, with burst onset at varying latency. The preeminential stimulus evokes a burst of spikes with a burst onset at $1.6 \mathrm{~ms} . c$ : preeminential fiber with bursts of spikes in response to the EOCD. The onset of the EOCD-evoked burst is more constant in this cell. The preeminential stimulus evokes a burst of 2 or 3 spikes at a burst onset latency of $\sim 3 \mathrm{~ms}$.

sistent with the origin of these fibers from the preeminential nucleus.

\section{Intracellular responses of ELL cells to activation of central afferents}

All of the major cell types that were described in the previous paper of this series (Mohr et al. 2003) were also tested for responses to electrical stimulation of the preeminential and juxtalobar nuclei.

MEDIUM GANGLIONIC CELLS (MG CELLS). We recorded the responses of $12 \mathrm{MG}$ cells to stimulation of the juxtalobar nucleus, of which 3 were morphologically identified MG1 cells and 4 were MG2 cells, and there were no clear differences between the responses of these two cell types. The responses of MG cells to juxtalobar stimulation were predominantly excit- atory and similar to the EOCD responses, as can be seen by comparing EOCD responses of Fig. 7A, left, with the juxtalobar responses (right). The responses to juxtalobar stimuli were, however, smaller in amplitude than the EOCD responses. The response to juxtalobar stimulation was consistently reduced when the stimulus was given at delays of $<40 \mathrm{~ms}$ after the command signal $(5$ cells, Fig. $7 B$ ), consistent with the similar refractoriness observed with field potentials and with the hypothesis that input from the juxtalobar nucleus is a major determinant of the EOCD response.

The latency to the peak of the EPSP in MG cells after juxtalobar stimulation ranged between 12 and $32 \mathrm{~ms}$. These latencies are about the same as the latencies from $t_{0}$ of the command signal to the peak of the EOCD response in MG cells. However, the juxtalobar input arrives at ELL at a latency of $\sim 5 \mathrm{~ms}$ following $t_{0}$, as described in the preceding text, and the latencies of the responses to artificial electrical stimulation of the juxtalobar nucleus are therefore $\sim 5 \mathrm{~ms}$ longer than might be expected under the hypothesis that the juxtalobar input is the major source of the EOCD responses of MG cells. The longer latency as well as the smaller size of the responses to artificial juxtalobar stimulation in comparison to the naturally occurring EOCD responses may be consequences of the
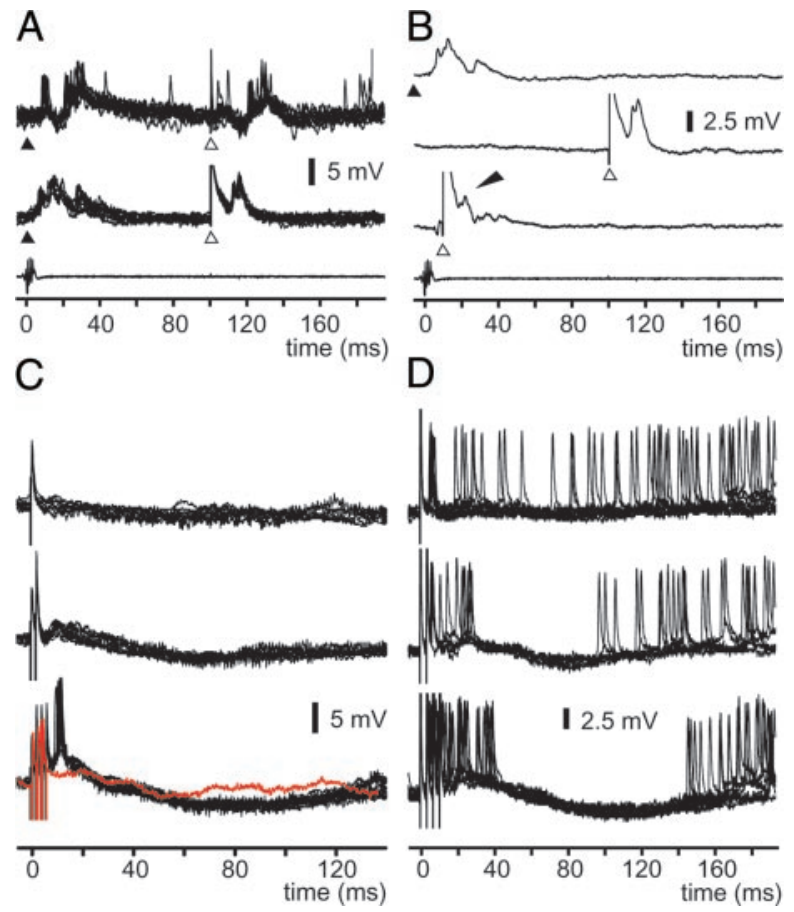

FIG. 7. Responses of medium ganglionic (MG) cells to juxtalobar and preeminential stimuli. $A$ : responses of $2 \mathrm{MG}$ cells to the EOCD and to juxtalobar stimuli. Note the similarities between the EOCD and juxtalobar responses. The responses to juxtalobar stimuli are much shorter than the EOCD responses in the 2nd set of traces. $B$ : depression of the response to juxtalobar stimulation when the stimulus is given at a short delay following $t_{0}$ (compare middle and bottom). Responses were averaged and the EOCD responses were subtracted from the middle and bottom. $C$ : responses of an MG cell to preeminential stimulation. Responses to 1, 2 , and 4 closely spaced stimuli are shown top to bottom. Interstimulus intervals were $2 \mathrm{~ms}$. The red line indicates the calculated response ( 4 times the response to a single stimulus) that would be expected if there were no facilitation. Note that both the EPSP and the IPSP in response to 4 stimuli are larger than the calculated response. $D$ : responses of a 2 nd MG cell to preeminential stimulation. Responses to 1,2 , and 4 closely spaced stimuli are shown top to bottom. Interstimulus intervals were $2 \mathrm{~ms}$. The EPSP of this cell is longer in duration and evokes more spikes that the EPSP in $C$. 

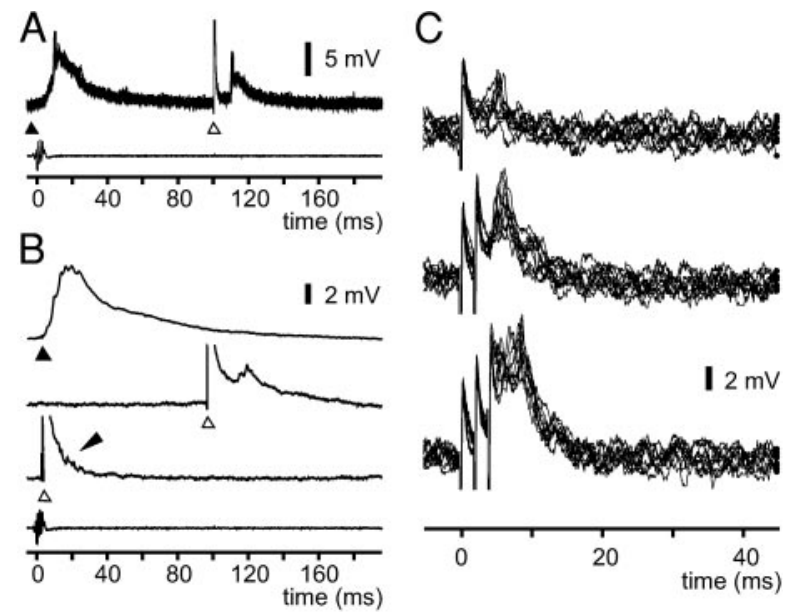

FIG. 8. Responses of thick smooth dendrite (TSD) cells to juxtalobar and preeminential stimuli. $A$ : responses to the EOCD and to juxtalobar stimuli. Ten superimposed traces. $B$ : depression of the response to juxtalobar stimuli when the stimulus is given at a short delay flowing $t_{0}$. Responses were averaged and the EOCD responses were subtracted in the middle and bottom to show the juxtalobar responses more clearly. $C$ : responses to preeminential stimulation. The stimulus evokes an EPSP but not an IPSP. The EPSP is facilitated by delivery of two or three closely spaced (2 ms) stimulus pulses. Ten superimposed traces.

difference between artificial activation of the nucleus and the activation which occurs with the naturally occurring EOCD (see DISCUSSION).

We recorded the responses of $35 \mathrm{MG}$ cells to preeminential stimulation. Eleven of these were identified as MG1 cells and eight were identified as MG2 cells based on their morphology or their responses to electrosensory stimuli (Mohr et al. 2003). Responses of the two subtypes to preeminential stimulation were similar, and results from all of the cells are described together.

All 35 MG cells responded to preeminential stimulation. Twenty-two cells responded to single stimulus with a short EPSP followed by a long IPSP (Fig. 7, $C$ and $D$ ), whereas 13 cells showed only an EPSP. The latency of the EPSP peak ranged between 2.0 and $7.4 \mathrm{~ms}$ (mean: $4.2 \pm 1.8 \mathrm{~ms}$ ). The EPSP evoked small narrow spikes or large broad spikes in some cells.

The synaptic responses to preeminential stimulation were strongly facilitated by delivering brief bursts of two to four stimuli at intraburst intervals of 2-4 ms (Fig. 7, $C$ and $D$ ) as described in the preceding text for the extracellularly recorded field potentials. Both EPSPs and IPSPs were facilitated. The EPSPs and IPSPs in response to brief bursts of two to four stimuli were clearly much larger than would be expected from the linear sum of responses to individual stimuli.

THICK SMOOTH DENDRITE (TSD) CELLS. We recorded the responses of four TSD cells to juxtalobar stimulation. All four responded with an EPSP that gave rise to a single spike or a burst of spikes (Fig. 8A). The responses of TSD cells to juxtalobar stimulation were quite similar to the EOCD responses as noted previously for MG cells. However, the initial slope of the EOCD response was more gradual than that of the juxtalobar response (compare Fig. 8A, left and right), suggesting that the initial part of the TSD EOCD response may not be due to juxtalobar input (see DISCUSSION). The latencies to the peak of the EPSP ranged from 10.4 to $22.3 \mathrm{~ms}$ in different cells. These TSD cell latencies were somewhat longer than would be expected from the latencies of the EOCD responses under the hypothesis that juxtalobar input is responsible for the EOCD responses, as described in the preceding text for $\mathrm{MG}$ cells. The effect of an immediately preceding EOCD response on the response to juxtalobar stimuli was tested in two cells. As in MG cells, the responses of TSD cells to juxtalobar stimuli were consistently and significantly reduced when the stimuli were given at delays of $<40 \mathrm{~ms}$ after the command signal (Fig. $8 B$, black arrowhead).

We examined the effect of preeminential stimulation in nine TSD cells. Seven of the nine cells responded with a brief, short-latency EPSP (mean latency of the peak: $4.6 \pm 2 \mathrm{~ms}$; Fig. $8 C$, top ). No IPSPs were evoked, and two cells did not respond at all. The EPSPs gave rise to small spikes in two of the five cells. The responses of TSD cells to preeminential stimuli, like the responses of MG cells, were strongly facilitated by delivering brief bursts of two to five stimuli at intraburst intervals of 2-4 ms (Fig. 8C, middle and bottom).

MEDIUM FUSIFORM CELLS. Medium fusiform cells responded to juxtalobar stimulation. Four of the five cells tested with such stimuli gave a simple EPSP that was quite similar to the EOCD-evoked EPSP (Fig. 9A). Latencies to the peak of the juxtalobar-evoked EPSPs were between 5.9 and $8 \mathrm{~ms}$. These latencies were 3-5 ms longer than would be expected from the latencies of the EOCD responses of medium fusiform cells under the hypothesis that juxtalobar input is responsible for the EOCD responses, as described in the preceding text for MG and TSD cells. The EPSP evoked by juxtalobar stimulation was smaller than the EOCD-evoked EPSP (Fig. 9, $A-C$ ). The amplitude of the juxtalobar EPSP was reduced $\sim 20 \%$ when stimuli were given at delays of $10 \mathrm{~ms}$ after the command signal (Fig. 9C).

We tested the effects of preeminential stimulation in six medium fusiform cells, but none of the cells responded to single stimuli or even to brief bursts of stimuli (data not shown). This lack of responsiveness is surprising because medium fusiform cells have an extensive dendritic arbor in the deep molecular layer (Han et al. 1999; Meek et al. 1996; Mohr et al. 2003), where fibers from the preeminential nucleus terminate. The lack of responsiveness suggests that preeminential
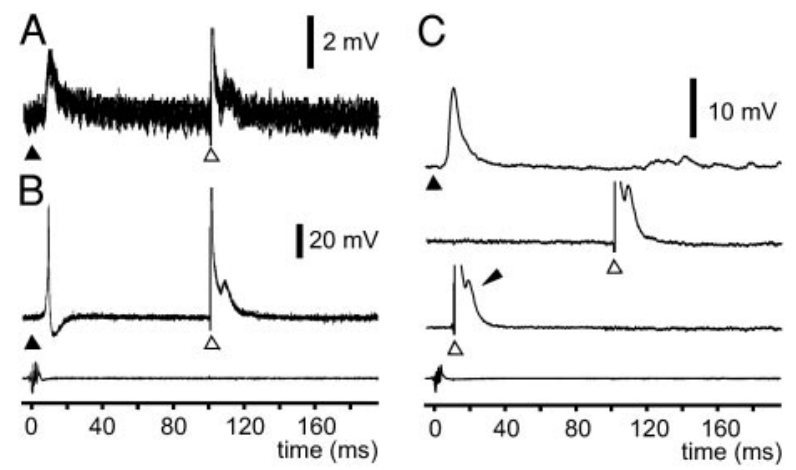

FIG. 9. Responses of medium fusiform cells to juxtalobar stimulation. A: responses of a medium fusiform cell to the EOCD and to juxtalobar stimuli. Ten superimposed traces. $B$ : responses of a 2 nd medium fusiform cell to the EOCD and to juxtalobar stimuli. The EOCD evokes a spike in this cell. $C$ : depression of the response to juxtalobar stimuli when the stimulus is given at a short delay after $t_{0}$. Responses were averaged and the EOCD response was subtracted from the 2 nd and 3rd traces to show the juxtalobar responses more clearly. 
fibers do not synapse with all the cells that have dendrites in their region of termination. Other possible inputs for medium fusiform cells in the deep molecular layer are parallel fibers from EGp (Bell and Szabo 1986) or some juxtalobar fibers (see Fig. 3).

EFFERENT CELLS. We tested the effects of juxtalobar stimuli on four large ganglionic and four large fusiform cells. Large ganglionic cells with excitatory EOCD responses were excited in a similar manner by juxtalobar stimuli (Fig. 10, $A$ and $B$ ). Large fusiform cells that responded with an IPSP to the EOCD also responded with an IPSP to juxtalobar stimuli (Fig. 10C), and large fusiform cells that responded with an EPSP to the EOCD responded with a similar EPSP to juxtalobar stimuli (Fig. 10D). Thus the responses of efferent cells to juxtalobar stimuli were similar in waveform to their EOCD responses, although usually smaller in amplitude and often shorter in duration. The responses of efferent cells to juxtalobar stimuli were reduced when the stimuli were given at delays of $\leq 20 \mathrm{~ms}$ after the command signal (Fig. 10, $B$ and $D$, bottom), as with the juxtalobar responses of other ELL cells.

We tested the effects of preeminential stimuli on 15 efferent cells -7 large ganglionic cells and 8 large fusiform cells. The responses of efferent cells to preeminential stimulation were similar to those of MG cells. A single stimulus elicited a brief short latency EPSP followed by a long-lasting IPSP (Fig. 10, $E$ and $F$ ). The EPSPs could give rise to spikes. Both EPSPs and IPSPs were facilitated by delivery of brief bursts of two to four stimuli (Fig. 10, $E$ and $F$, middle and bottom).

PRIMARY MORMYROMAST AFFERENTS AND GRANULAR CELLS. Granular cells of ELL have not yet been recorded from intracellularly in vivo. However, recordings from primary mormyromast afferent fibers near their central terminals show various types of synaptic potentials (Bell 1990). The synaptic potentials reflect synaptic input to ELL granular cells that is observed inside the afferents because of the electrical synapses that the afferents make on granular cells (Bell et al. 1989). We therefore recorded from mormyromast fibers in the deep layers of ELL to examine synaptic inputs to ELL granular cells.

Juxtalobar stimuli evoke a brief short-latency EPSP in afferent fibers that is very similar to the EOCD-evoked EPSP that is also observed in afferent fibers (Fig. 11A). The latencies to the peak of the juxtalobar-evoked EPSPs were between 4.2 and $11.5 \mathrm{~ms}$ (20 fibers; Fig. 11A). Most of these latencies were 2-4 ms longer than would be expected under the hypothesis that the EOCD response is due to input from the juxtalobar nucleus. The juxtalobar EPSP was markedly reduced when stimuli were given at delays of $<20 \mathrm{~ms}$ after the command signal (Fig. $11 B)$.

We examined the effect of preeminential stimulation on 20 intracellularly recorded afferent fibers from mormyromast electroreceptors, but none of the cells responded to single stimuli or even to brief bursts of stimuli. This lack of responsiveness is consistent with the lack of input from the ipsilateral preeminential nucleus to the deeper layers of ELL where the granular cells are located. Disynaptic responses of granular cells to preeminential stimulation might be expected, however, because TSD cells project to the granular layer and are excited by preeminential stimuli. Preeminential stimuli did not always evoke spikes in TSD cells, and it is possible that our preeminential stimulation did not evoke a sufficiently large response
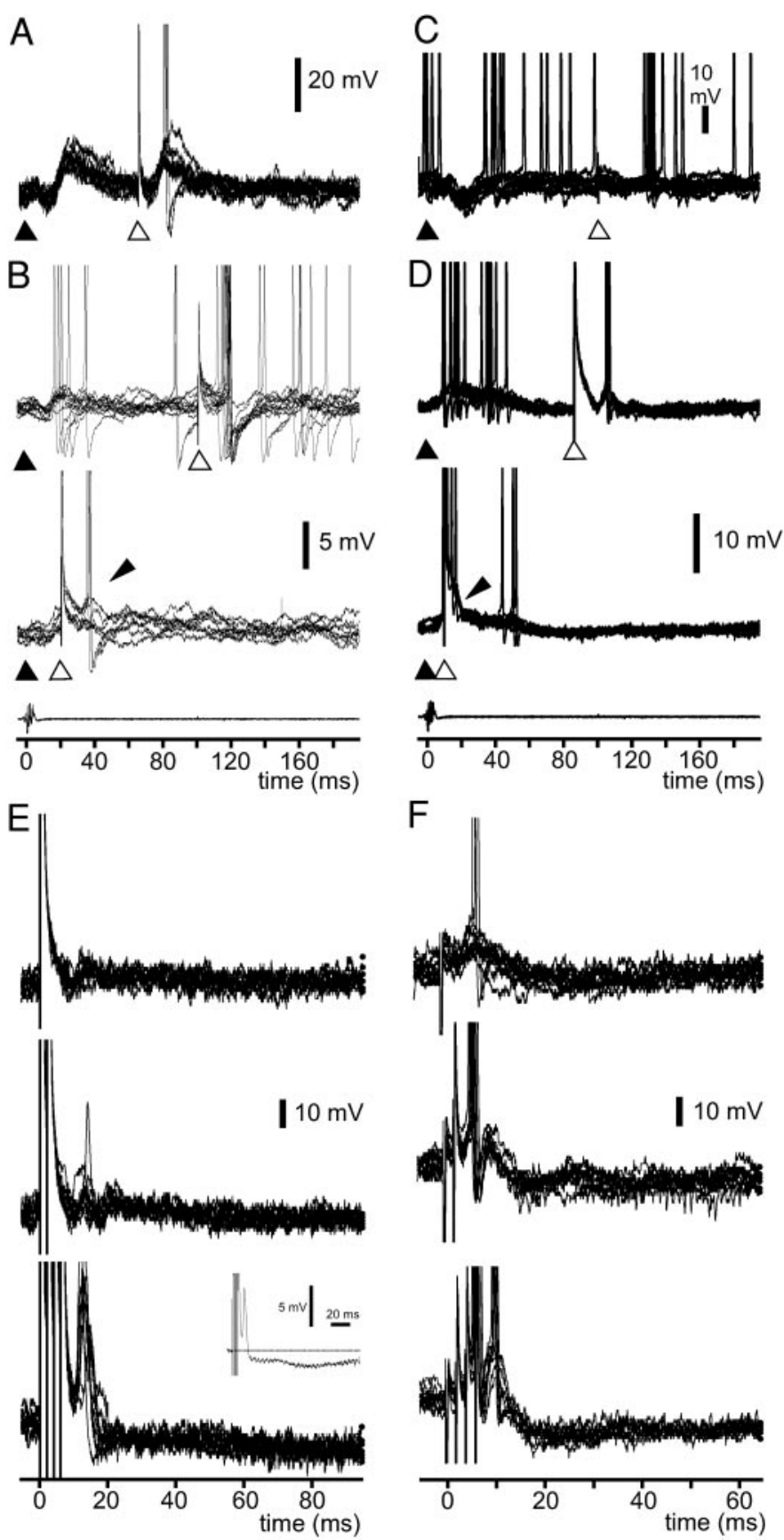

FIG. 10. Responses of efferent cells to juxtalobar and preeminential stimuli. A: large ganglion cell responds to the EOCD and to juxtalobar stimuli with EPSPs. The juxtalobar stimulus evokes a spike in some sweeps. B: large ganglion cell responds to the EOCD and to juxtalobar stimuli with a small EPSP. The response to juxtalobar stimuli is larger when the stimulus is given at a long delay of $100 \mathrm{~ms}$ (top) than when it is given at a short delay of $20 \mathrm{~ms}$ (bottom). C: large fusiform cell, which responds to the EOCD and to juxtalobar stimuli with a small IPSP. The IPSP in response to juxtalobar stimuli is smaller. $D$ : large fusiform cell that responds to the EOCD and juxtalobar stimuli with an EPSP. The response to juxtalobar stimuli is more pronounced when the stimulus is delivered at a delay of $100 \mathrm{~ms}$ after $t_{0}$ (top) than when it is delivered at $10 \mathrm{~ms}$ after $t_{0}$ (bottom). E: large ganglion cell that responds to preeminential stimuli with an EPSP followed by an IPSP. Responses to 1, 2, and 4 closely spaced $(2 \mathrm{~ms})$ stimuli are shown. The IPSP only becomes obvious in this cell with 4 stimuli (bottom). Inset: an average of the response to 4 stimuli to emphasize the IPSP in the response. $F$ : large fusiform cell that responds to preeminential stimuli with an EPSP followed by an IPSP. Responses to 1,2 , and 4 closely spaced ( $2 \mathrm{~ms}$ ) stimuli are shown. 

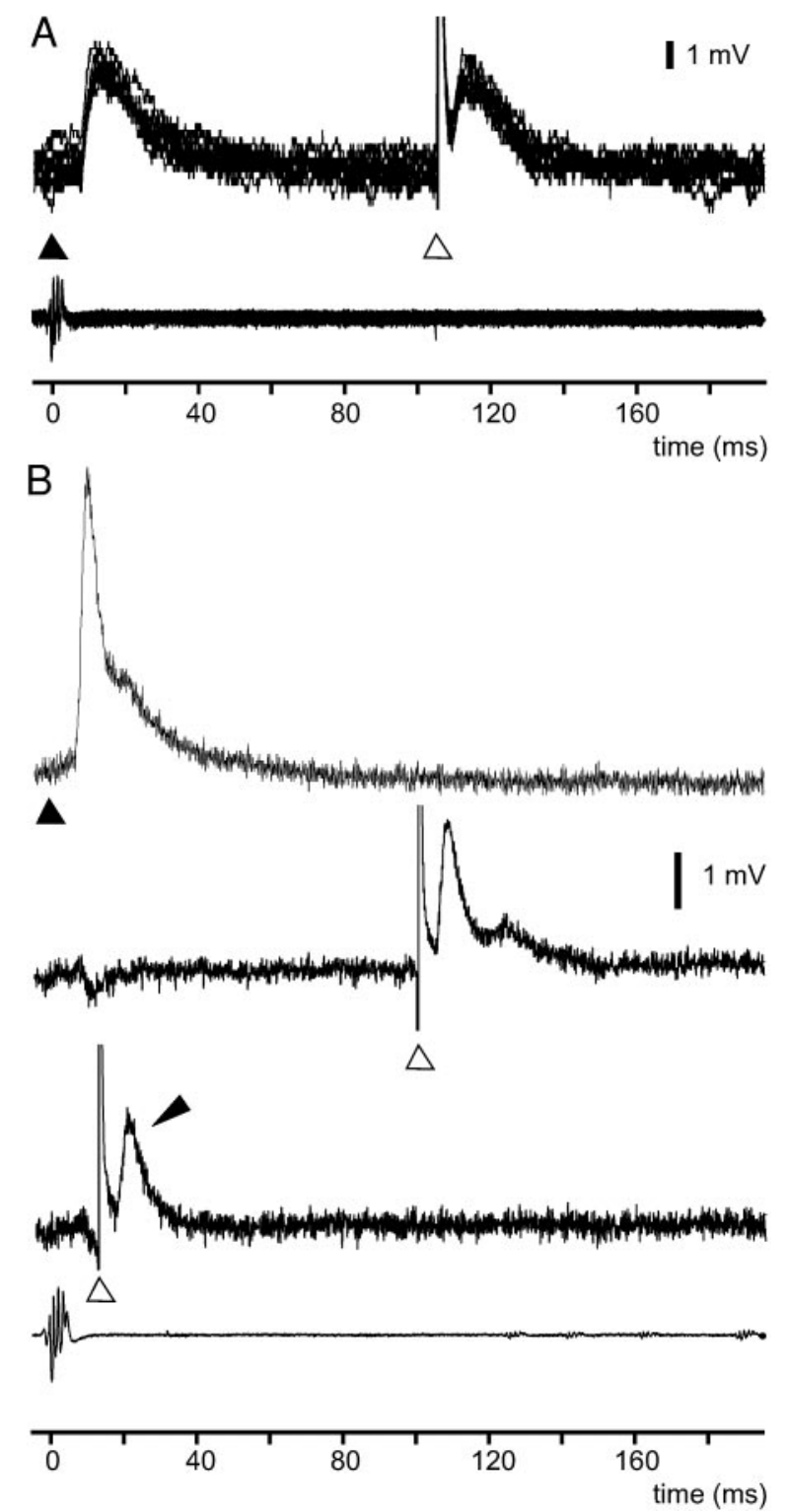

FIG. 11. Responses of primary afferents to juxtalobar stimulation. A: responses of primary afferent fiber to EOCD and to juxtalobar stimuli. Note the similarity of the 2 EPSPs. $B$ : depression of the response to juxtalobar stimuli in a different primary afferent fiber when the stimulus is given at a short delay following $t_{0}$. Responses were averaged. Top: EOCD response. Middle: response to juxtalobar stimulus given at 100-ms delay. Bottom: response to juxtalobar stimulus given at 15-ms delay. The response to EOCD alone was subtracted from middle and bottom to show the juxtalobar response more clearly.

in TSD cells to elicit synaptic responses in granular cells. It is also possible that TSD cells do not make extensive contacts with granular cells.

\section{I S C U S S I O N}

This paper describes the responses of ELL cells to the stimulation of preeminential and juxtalobar nuclei, two of the three major descending inputs to ELL from other central structures. The effects of activating the third major central input to ELL, the parallel fibers from the eminentia granularis posterior (EGp), were examined in a previous in vitro study (Bell et al. 1997; Grant et al. 1998; Han et al. 2000).
Effects of juxtalobar stimuli on ELL cells

The juxtalobar responses of ELL cells were quite similar in waveform to their EOCD responses. This similarity suggests that the juxtalobar input is a major determinant of the responses of ELL cells to the EOCD alone. The reduction of field potential and intracellularly recorded juxtalobar responses when stimuli were delivered $<20 \mathrm{~ms}$ after the command signal indicates refractoriness and is therefore consistent with this conclusion.

The responses to juxtalobar stimuli were generally smaller than the EOCD responses, but this smaller size is probably due to the fact that EOCD responses are evoked by the synchronous activation of all the cells in both the left and right juxtalobar nuclei because each juxtalobar nucleus projects bilaterally to ELL. Our artificial juxtalobar stimuli, however, were delivered to only one of the two nuclei and probably activated only some of the cells in the stimulated nucleus.

The hypothesis that the EOCD-evoked responses of ELL cells are due to juxtalobar input would seem to require that the latency to the peak of the response to juxtalobar stimulation be $5.6 \mathrm{~ms}$ shorter than the latency from $t_{0}$ of the command signal to the peak of the EOCD response because juxtalobar input arrives at the ELL at a delay of $\sim 5.6 \mathrm{~ms}$ after $t_{0}$. But the latencies to the peak of the response to juxtalobar stimulation were consistently longer than this by $2-6 \mathrm{~ms}$. This difference could also be due to differences between artificial activation and EOCD activation of the nucleus. Artificial activation could cause stimulation of afferent fibers to the nucleus (Gustafsson and Jankowska 1976), and activation time in the nucleus could also be a few milliseconds. Synchronous activation of a smaller number of juxtalobar fibers with our artificial stimulus than with the normal EOCD could also result in a more slowly rising postsynaptic response in ELL.

The juxtalobar nucleus has a medial part that affects ELL via the direct projection described in the preceding text (Fig. 3) and a lateral part that affects ELL indirectly via a projection to EGp (Fig. 1) (Bell et al. 1981). Although it is assumed that the direct effect of the medial juxtalobar nucleus is stronger than the indirect effect of the lateral juxtalobar nucleus, this has not been demonstrated, and the indirect effect via EGp and the parallel fibers of ELL may also contribute to the juxtalobar responses in ELL.

\section{Effects of preeminential stimuli on ELL cells}

The preeminential nucleus affects ELL via three different pathways: the prominent projection to the deep molecular layer of ELL, the equally prominent but indirect projection through EGp, and the less prominent and only poorly understood direct projection to the granular layer of ELL (Bell et al. 1981). We infer that the effects we observed were predominantly due to activation of the preeminential projection to the deep molecular layer of ELL because of the field potentials evoked by our stimulus and because of the ipsilateral location of our stimulus electrode as described in METHODS.

Medium ganglionic cells and efferent cells responded to preeminential stimulation with a brief short-latency EPSP followed by a long-lasting IPSP, whereas TSD cells responded with only an EPSP. The short-latency EPSP indicates that preeminential input to ELL is excitatory, as does the short- 
latency, sharply negative field potential. Electron microscopy of labeled preeminential fibers in ELL also indicates that these synapses are excitatory (Meek 1993). The IPSPs that follow the EPSPs are presumed to be due to activation of inhibitory interneurons in ELL that contact medium ganglion cells and efferent cells but that may not contact TSD cells. Medium ganglion cells themselves are good candidates for such interneurons because they are GABAergic and contact other medium ganglion cells, as well as efferent cells.

The EPSPs, IPSPs, and field potentials evoked by preeminential stimuli were all markedly facilitated when brief bursts of two to five stimuli were delivered. Similar results have been found in the ELL of gymnotiform electric fish where brief bursts of stimuli result in marked facilitation of the EPSPs and IPSPs evoked in ELL pyramidal cells by preeminential stimuli (Bastian 1998; Oswald et al. 2002).

The facilitation is functionally important because preeminential cells respond to the EOCD with bursts that are similar in frequency and number of spikes to the bursts of artificial stimuli used here (von der Emde and Bell 1996). The EOCD bursts of preeminential cells may be either increased (E cells) or decreased (I cells) in number of spikes by electrosensory stimuli in the receptive field of the cell. The synaptic facilitation shown here will enhance the responses of ELL cells to the EOCD-driven bursts. Moreover, the facilitation will also magnify the effect of changes in the number of spikes in preeminential EOCD responses that are caused by electrosensory input. The effect of adding or subtracting one or two spikes of the EOCD-evoked burst will be greater because of the facilitation.

The axons of ELL efferent cells give off collaterals to the preeminential nuclei before they terminate in the lateral toral nucleus of the mesencephalon. The efferent cells of ELL are glutamatergic (Grant et al. 1996) and therefore probably excitatory. Our electrophysiological findings as well as anatomical results (Meek 1993) indicate that preeminential input to the deep molecular layer of ELL is excitatory. These excitatory connections suggest that the mormyrid preeminential nucleus could provide positive feedback that would enhance and perhaps prolong the responses of ELL cells to sensory stimuli. Positive feedback has also been suggested as a role for the preeminential nucleus in gymnotiform fish (Bastian 1996). It should be noted, however, that some ELL efferent cells are excited by electrosensory stimuli (E cells), whereas others are inhibited (I cells). Similarly, the EOCD responses of some preeminential cells are increased by electrosensory stimuli (E cells), whereas the responses of others are decreased (I cells). Positive feedback from the preeminential nucleus therefore requires a high degree of cell-to-cell specificity. E cells from ELL would have to connect predominantly with preeminential E cells, which would in turn have to feedback predominantly onto E cells of ELL. The same would have to be true for I cells in the two structures. Such cell-type-specific termination patterns have not yet been demonstrated, although the possibility of some cell-type-specific connectivity in the deep molecular layer was suggested by the lack of responsiveness of medium fusiform cells to preeminential input even though these cells have a rich dendritic arbor in the deep molecular layer where preeminential fibers terminate.

Positive feedback from ELL cells to preeminential cells and back to ELL cells may be an important part of preeminential function, but this is not yet demonstrated. The preeminential nucleus receives a massive input from the lateral nucleus of the torus semicircularis as well as the valvula cerebelli. The lateral toral nucleus is the major termination site for efferent axons from ELL and also receives extensive input from the tectum, the telencephalon and the valvula cerebelli. The relative roles and importance of inputs from ELL, the valvula and the lateral toral nucleus in determining the responses of preeminential cells are as yet unknown.

Unlike the juxtalobar nucleus, the preeminential nucleus does not appear to make a major contribution to the responses of ELL cells to the EOCD alone. This was suggested by a previous study that found little similarity between EOCD- and preeminential-evoked field potentials in the different layers of ELL (Bell and von der Emde 1995). Our intracellular recordings of EOCD responses are consistent with this suggestion. The preeminential responses of MG cells, large ganglionic cells, large fusiform cells with inhibitory EOCD responses, and large fusiform cells with excitatory EOCD responses to preeminential stimuli were all quite similar-a brief, short-latency EPSP followed by a long-lasting IPSP. The EOCD responses of these ELL cells were quite different from their preeminential responses, however, and also quite different from each other.

\section{Overview of the origins of EOCD responses in ELL}

The fibers from the juxtalobar nuclei that we recorded in the granular layer of ELL responded to the EOCD with single spikes at latencies of 5.6-5.8 ms. The intracellularly recorded EOCD responses of most ELL cells were slightly later than this, indicating that they could be evoked either monosynaptically or polysynaptically by the juxtalobar input (Fig. 12). These latency results are consistent with the results obtained with artificial stimulation of the juxtalobar nucleus and the conclusion that was based on the stimulation results of a major role for juxtalobar input in determining the EOCD responses of ELL cells.

In contrast to other ELL cells, TSD cells had EOCD responses with latencies $(2.5-4.2 \mathrm{~ms})$ that were significantly earlier than the latency of juxtalobar fibers. The initial portion, at least, of the EOCD response of TSD cells could not have been evoked by juxtalobar input (arrow in Fig. 12C). Some of the inputs to EGp have EOCD responses as early as $3.0 \mathrm{~ms}$ before time 0 , and some parallel fibers might therefore be activated early enough to account for the early onset of the EOCD-evoked EPSP in TSD cells. One would expect, however, that if parallel fiber excitation were responsible for the early EOCD response of TSD cells, then other cells with dendrites in the molecular layer would also show an early EOCD response, but they did not. Thus the origin of the initial part of the EOCD response of TSD cells is uncertain.

EOCD responses of granular cells (as observed in intracellular recordings from primary mormyromast afferents) and medium fusiform cells consisted of brief, stereotyped EPSPs at short, fixed latencies $(5.4$ and $5.5 \mathrm{~ms}$ for mean latencies of granular cells and medium fusiform cells, respectively) (Mohr et al. 2003). These latencies are close enough to the latencies of the juxtalobar fibers recorded in ELL to be consistent with monosynaptic excitation of these cells by EOCD-driven juxtalobar input, given the variability between animals and between different regions of ELL. The excitatory EOCD responses of 


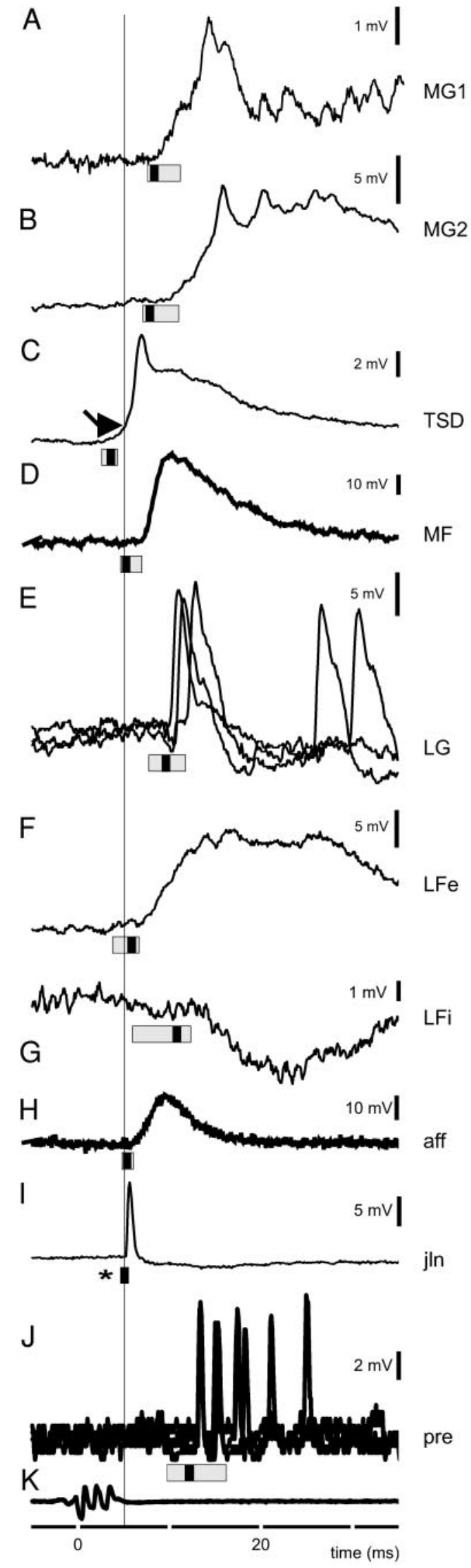

large fusiform cells (Fig. 12F) were also quite short and could also have been evoked by direct input from the juxtalobar nucleus.

The latencies of EOCD responses in other ELL cells were longer and more variable than those in TSD, medium fusiform, and granular cells. The mean latency of the EOCD responses in medium ganglionic cells, for example, was $8.5 \mathrm{~ms}$. The responses were also much less stereotyped. The longer latencies and more variable responses suggest that the juxtalobar effects on these other cells were mediated by as yet unidentified ELL interneurons.

The mean latencies of EOCD responses in all ELL cells were shorter than the mean latency of EOCD responses in preeminential cells $(13.3 \mathrm{~ms})$ or the mean latency of presumed preeminential fibers in the deep molecular layer of ELL (12.3 ms; Fig. 12J). Thus the initial portions, at least, of EOCD responses in ELL cells cannot be due to preeminential input, a finding that is consistent with the results obtained with artificial stimulation of the preeminential nucleus as described in a previous section and with the results of a previous field potential study (Bell and von der Emde 1995).

One would expect a more obvious contribution of preeminential input to the EOCD responses of ELL cells because the projection from the preeminential nucleus to ELL is a major one and most preeminential cells have EOCD responses. Part of the explanation is that the EOCD-driven responses of different preeminential cells have different latencies (range: $10-16 \mathrm{~ms}$ ), and the responses of some individual preeminential cells vary in latency. Such variability would make the effect of preeminential input less obvious. The later components of EOCD responses to the EOCD are probably influenced by preeminential input. But the nature of this preeminential influence is not known and may not be very large because juxtalobar lesions reduce the later components of EOCD-evoked field potentials by $\geq 70 \%$ (Bell and von der Emde 1995).

The third source of EOCD-related input to ELL, the eminentia granularis posterior (EGp), was not investigated in this study. EOCD responses of various types are recorded in EGp that probably represent the activity of fibers, which terminate in EGp (Bell et al. 1992). The EOCD responses of parallel fibers themselves are not yet known. As described previously, the lateral half of the juxtalobar nucleus projects to EGp, and we do not know how much of the effect of the juxtalobar nucleus is mediated by the medial half of the nucleus which projects directly to ELL and how much of the effect is medi-

FIG. 12. Summary figure showing the relative timing of EOCD responses in different ELL cells and central afferents. Each trace shows the EOCD response of 1 cell of a given type. The gray bar beneath each trace shows the range of EOCD response onset times for cells of that type. The thick black line within each gray bar shows the mean onset time for cells of that type. The EOCD-evoked field potential just outside the recorded cell has been subtracted from those that show averaged responses. The vertical line indicates the time of arrival of juxtalobar input in ELL. MG1, medium ganglionic cell type 1 (averaged response); MG2, medium ganglionic cell type 2 (averaged response); TSD, thick smooth dendrite cell (averaged response, note the early onset at arrow); MF, medium fusiform cell (averaged response); LG, large ganglionic cell (4 sample traces); LFe, large fusiform cell with EPSP as EOCD response (averaged response); Lfi, large fusiform cell with IPSP as EOCD response (averaged response); aff, primary afferent (averaged response); jln, extracellularly recorded juxtalobar fiber (averaged response); preextracellularly recorded preeminential fiber with 3 sample traces. 
ated by the indirect projection to ELL from the lateral half of the nucleus through EGp.

In summary, our results from intracellular recording of ELL cells and stimulation of central afferents are consistent with previous results showing that responses to the EOCD alone in ELL are driven predominantly by input from the juxtalobar nucleus. The short, fixed latency of many EOCD responses suggests that they are driven by the direct input from the juxtalobar nucleus to ELL rather than by the indirect input through EGp and the parallel fibers of ELL, but this is not yet clearly established. EOCD signals from EGp, mediated by other inputs to EGp than that from the juxtalobar nucleus as well as EOCD signals from the preeminential nucleus must also affect ELL cells because EOCD-evoked field potentials are still present in ELL after bilateral juxtalobar lesions, although the potentials are markedly reduced and altered in waveform by the lesions.

\section{Flow of electrosensory and EOCD information through ELL}

Two precisely timed pulse-like events, the EOD itself and the EOD motor command via the EOCD, affect the mormyromast regions of ELL at the time of the EOD. The EOD activates afferent fibers from mormyromast electroreceptors that terminate in the granular layers of ELL. The EOD motor command activates three different central structures that send various EOCD signals to ELL. Much is now known about the anatomy and physiology of ELL circuitry. Given this knowledge of the circuitry and the pulsatile character of the two inputs, it should be possible to determine the flow of peripheral and central information through the circuitry by analyzing the relative timing of the responses of different cell types to the two inputs, as illustrated for electrosensory responses in Fig. 15 of the first paper and for EOCD responses in Fig. 12 of this paper. There are two reasons why such a comprehensive description of the flow of information through ELL is not yet possible.

The first reason is the variability in the responses of different cells of the same type to electrosensory and EOCD inputs. The variability in the timing of responses to these inputs for the same cell type, across different fish and in different ELL regions of the same fish, is remarkably low, but it is still too great to be certain that electrosensory or EOCD responses in a given cell type precede or follow the responses in another cell type and by how many milliseconds or synaptic delays. One method for reducing such variability would be to record sequentially from two different cell types in the same local region of ELL in the same fish and to make inferences about relative timing based on pairs of such recordings.

The second reason why it is not yet possible to give a comprehensive description of the flow of peripheral and central information through ELL circuitry is that the responses of some important cellular elements in ELL are not established. ELL granular cells, for example, are the major termination site for electrosensory afferents and the first site of interaction between electrosensory and EOCD signals, but their responses are only poorly understood. Granular cells of the deep and superficial granular layer are quite different in their morphology, immunohistochemistry, and connectivity, but nothing is known about the physiological differences between these two cell types or whether the synaptic responses recorded inside primary afferent fibers arise from one or both types of granular cells. The responses of other important elements are also not yet known, including the responses of parallel fibers, stellate cells of the molecular layer, and large multipolar neurons of the intermediate layer (Meek et al. 2001). If variability can be reduced and if the responses of all the important elements can be determined, then it should be possible to develop a comprehensive description of the flow of electrosensory and EOCD signals through the mormyrid ELL.

Even though a comprehensive description of the interaction between electrosensory and EOCD signals in ELL is not yet possible, the present study together with previous studies do suggest some general principles regarding the interaction between these two types of signals. Information processing in the mormyrid ELL may be divided into two stages: an initial stage in the deeper layers of ELL where the EOCD effects are stereotyped, relatively fixed (not plastic), and largely due to monosynaptic input from the juxtalobar nucleus and a later stage in the more superficial layers of ELL, where the EOCD responses are variable, plastic, and due to EOCD driven input from all three sources of central input, the EGp, the preeminential nucleus, and the juxtalobar nucleus.

The stereotyped EOCD input from the juxtalobar nucleus to the deeper layers of ELL appears to have two functions: selective enhancement of the electrosensory input that is evoked by the EOD (and that is therefore critical for active electrolocation) and the decoding of afferent response latency as a measure of stimulus intensity (Meyer and Bell 1983; Hall et al. 1995). Stimulus intensity appears to be encoded in primary mormyromast afferents as response latency (Szabo and Hagiwara 1967), and this latency is probably transformed into a burst frequency or burst duration code in ELL granular cells through an interaction between the primary afferent and juxtalobar inputs to these cells. The EOCD-gated and intensitymodulated bursts of granular cell activity are then conveyed to the next stage, the higher-order cells of ELL, in the more superficial layers of ELL.

Similarity of the responses of higher-order ELL cells to the EOCD and to juxtalobar input suggested that the responses of these cells to the EOCD alone, in the absence of any recent pairing with electrosensory stimuli, are largely due to juxtalobar input. The latency and variability of the EOCD responses in medium ganglion and efferent cells suggested that the juxtalobar effect on these cells is polysynaptic through ELL interneurons rather than monosynaptic. Our hypothesis is that the responses of these higher order cells to juxtalobar input is not plastic and that the EOCD plasticity shown by these cells is instead due to changes in synaptic efficacy at parallel fiber or preeminential synapses. Plasticity at parallel fiber synapses has been demonstrated in both mormyrid (Bell et al. 1997) and gymnotid (Bastian 1998) fish. Plasticity at preeminential synapses has been demonstrated in gymnotid (Bastian 1998) but not in mormyrid fish. Our hypothesis then is that the EOCD responses of higher-order ELL cells represent the summation of nonplastic input from the juxtalobar nucleus with plastic input from parallel fibers and possibly from preeminential fibers. The plasticity of higher-order ELL cells allows the system to remove predictable, and thus redundant, features from the sensory inflow (Bell et al. 1997). 


\section{I S C L OS URES}

This research was supported by a grant from the National Institute of Mental Health to C. C. Bell (MH-60996) and a grant from the National Science Foundation to P. D. Roberts (IBN 0114558).

\section{REFERENCES}

Bastian J. Plasticity in an electrosensory system. II. Postsynaptic events associated with a dynamic sensory filter. J Neurophysiol 76: 2497-2507, 1996.

Bastian J. Plasticity in an electrosensory system. III. Contrasting properties of spatially segregated dendritic inputs. J Neurophysiol 79: 1839-1857, 1998.

Bell CC. Mormyromast electroreceptor organs and their afferents in mormyrid electric fish. II. Intra-axonal recordings show initial stages of central processing. J Neurophysiol 63: 303-318, 1990.

Bell CC, Bodznick D, Montgomery J, and Bastian J. The generation and subtraction of sensory expectations within cerebellum-like structures. Brain Behav Evol 50, Suppl: 17-31, 1997.

Bell CC, Finger TE, and Russell CJ. Central connections of the posterior lateral line lobe in mormyrid fish. Exp Brain Res 42: 9-22, 1981.

Bell CC, Grant K, and Serrier J. Sensory processing and corollary discharge effects in the mormyromast regions of the mormyrid electrosensory lobe. I. Field potentials, cellular activity in associated structures. J Neurophysiol 68: 843-858, 1992.

Bell CC, Han VZ, Sugawara S, and Grant K. Synaptic plasticity in a cerebellum-like structure depends on temporal order. Nature 387: 278-281, 1997.

Bell CC and Szabo T. Electroreception in mormyrid fish: central anatomy. In: Electroreception, edited by Bullock TH and Heiligenberg W. New York: Wiley, 1986, p. 375-421.

Bell CC and von der Emde G. Electric organ corollary discharge pathways in mormyrid fish. II. The medial juxtalobar nucleus. J Comp Physiol [A] 177: 463-479, 1995.

Bell CC, Zakon H, and Finger TE. Mormyromast electroreceptor organs and their afferent fibers in mormyrid fish. I. Morphology. J Comp Neurol 286: 391-407, 1989.

Berman NJ, Plant J, Turner RW, and Maler L. Excitatory amino acid receptors at a feedback pathway in the electrosensory system: implications for the searchlight hypothesis. J Neurophysiol 78: 1869-1881, 1997.

Grant K, Meek J, Sugawara Y, Veron M, Denizot JP, Hafmans J, Serrier J, and Szabo T. Projection neurons of the mormyrid electrosensory lateral line lobe:morphology, immunocytochemistry and synaptology. J Comp Neurol 375: 18-42, 1996.

Grant K, Sugawara S, Gomez L, Han VZ, and Bell CC. The mormyrid electrosensory lobe in vitro: physiology and pharmacology of cells and circuits. J Neurosci 18: 6009-6025, 1998.

Gustafsson B and Jankowska E. Direct and indirect activation of nerve cells by electrical pulses applied extracellularly. J Physiol 258: 33-61, 1976.

Han VZ, Bell CC, Grant K, and Sugawara Y. Mormyrid electrosensory lobe in vitro: morphology of cells and circuits. J Comp Neurol 404: 359-374, 1999.

Han VZ, Grant K, and Bell CC. Reversible associative depression and nonassociative potentiation at a parallel fiber synapse. Neuron 27: 611-622, 2000.

Hall C, Bell C, and Zelick R. Behavioral evidence of a latency code for stimulus intensity in mormyrid electric fish. J Comp Physiol, 177: 29-39, 1995.

Maler L. The posterior lateral line lobe of a mormyrid fish — a Golgi study. J Comp Neurol 152: 281-298, 1973.

Meek J. Structural organization of the mormyrid electrosensory lateral line lobe. J Comp Physiol A Sens Neurol Behav Physiol 173: 675-677, 1993.

Meek J, Grant K, Sugawara S, Hafmans TGM, Veron M, and Denizot JP. Interneurons of the ganglionic layer in the mormyrid electrosensory lateral line lobe: morphology, immunocytochemistry, and synaptology. J Comp Neurol 375: 43-65, 1996

Meek J, Hafmans TGM, Han VZ, Bell CC, and Grant K. Myelinated dendrites in the mormyrid electrosensory lobe. J Comp Neurol 431: 255275, 2001.

Meyer JH and Bell CC. Behavioral measurement of sensory gating by a corollary discharge. J Comp Physiol 151: 401-406, 1983.

Mohr C, Roberts PD, and Bell CC. The mormyromast region of the mormyrid electrosensory lobe. I. Responses to corollary discharge and electrosensory stimuli. J Neurophysiol 90: 1193-1210, 2003.

Oswald AM, Lewis JE, and Maler L. Dynamically interacting processes underlie synaptic plasticity in a feedback pathway. J Neurophysiol 87: 2450-2463, 2002.

Szabo T and Hagiwara SA. A latency-change mechanism involved in sensory coding of electric fish (mormyrids). Physiol Behav 2: 331-335, 1967.

von der Emde $\mathbf{G}$ and Bell $\mathbf{C}$. Nucleus preeminentialis of mormyrid fish, a center for recurrent electrosensory feedback. I. Electrosensory and corollary discharge responses. J Neurophysiol 76: 1581-1596, 1996. 